\title{
PROLONGED CARDIOPULMONARY BYPASS FOR SEVERE DRUG INTOXICATION
}

\author{
Miralem Pasic, MD, PhD, FETCS, Evgenij Potapov, MD, Hermann Kuppe, MD, PhD and Roland Hetzer, MD, PhD,
} Berlin, Germany

Cardiopulmonary bypass (CPB), a standard procedure in cardiac surgery, has been only exceptionally used for treatment of severe drug intoxication, with mostly poor results. ${ }^{1-5}$ We report on the successful use of a very long duration of $\mathrm{CPB}$ for severe intoxication with the antiarrhythmic drug prajmalium.

Clinical summary. A 25-year-old hospitalized woman took 16 tablets $(320 \mathrm{mg}$ ) of prajmalium bitartrate (Neo-Gilurytmal) with the possible intention of committing suicide. The first cardiac manifestation was a very short period of bradyarrhythmia, followed by electromechanical dissociation and ventricular fibrillation. The estimated interval between drug intake and the beginning of the symptoms was between 10 and 45 minutes. The intractable electrical and hemodynamic instabilities were refractory to all conventional therapies including several attempts to terminate ventricular fibrillation by electrical defibrillation. The patient was intubated, ventilated, and transferred to the operating room while undergoing external manual heart massage. Standard normothermic CPB was established through a median sternotomy with cannulation of the ascending aorta and the right atrium. The total time from the beginning of the cardiopulmonary resuscitation to the initiation of CPB was 45 minutes. During CPB, direct cardiac electrical defibrillation was undertaken every $10 \mathrm{~min}$ utes to terminate ventricular fibrillation but all attempts failed. After 55 minutes of CPB, ventricular fibrillation converted spontaneously into sinus rhythm. Elevations of the ST interval and very high $\mathrm{T}$ waves were seen for the following 4 hours, and the electrocardiographic findings improved thereafter. Since there is no specific treatment for intoxication with this particular drug, we added several general therapeutic measures such as gastric lavage, forced diuresis (in total $11 \mathrm{~L}$

From Deutsches Herzzentrum, Berlin, Germany.

Received for publication Sept 8, 1999; accepted for publication Oct 6, 1999.

Address for reprints: Miralem Pasic, MD, PhD, FETCS, Deutsches Herzzentrum Berlin, Augustenburger Platz 1, D-13353, Berlin, Germany (E-mail: pasic@dhzb.de).

J Thorac Cardiovasc Surg 2000;119:379-80

Copyright (C) 2000 by Mosby, Inc.

$0022-5223 / 2000 \$ 12.00+0 \quad \mathbf{1 2 / 5 4 / 1 0 3 4 6 3}$ during $\mathrm{CPB}$ ), ultrafiltration (37 L), and hemoabsorption with a charcoal filter inserted in the CPB circuit. After 6 hours of reperfusion, the first attempt at discontinuation of $\mathrm{CPB}$ was undertaken but it failed to establish stable hemodynamics. The predominant cause was right-sided heart failure, which appeared despite administration of inotropic support, inhalation of nitric oxide for lowering the pulmonary vascular resistance, and implantation of an intra-aortic balloon counterpulsation device. The hemodynamic instability was stressed by initiation of intermittent ventricular fibrillation with the heart volume loaded. It was only after a total of 1000 minutes (16 hours 40 minutes) of reperfusion that a persistent stable hemodynamic situation was achieved after cessation of CPB. The duration of reperfusion necessary to achieve optimal hemodynamics correlated well with the retrospectively estimated half-life of the ingested drug. Assessed by its plasma concentrations, the half-life of prajmaline was 16 hours 43 minutes, almost exactly the length of CPB. The postoperative course was uneventful except for a prolonged neurologic recovery. During her hospital stay, she had ataxic walk and expressed disturbances of cognitive functions, affect instability, and mood disorder. On the 35 th postoperative day she was discharged to a neuropsychiatric rehabilitation facility. Echocardiography showed good functioning of the heart with only slightly reduced contractility of the right ventricle.

Comment. Prolonged CPB was the only therapeutic solution for resuscitation because the patient needed more than 16 hours of reperfusion to achieve recovery and stabilization of the mechanical and electrical function of the heart. We used conventional $\mathrm{CPB}$, which allowed for excellent heart venting and prevented the highly dangerous risk of right and left ventricular dilation. A possible alternative is percutaneous CPB, which can be instituted through femoral vessels. This procedure does not require that the chest be opened, but it includes several important disadvantages such as possible dangerous distention of the cardiac ventricles, damage of the peripheral vessels, ischemic leg complications, and hemorrhage. In some instances it cannot be applied because of atherosclerotic vascular changes or a small diameter of the vessels.

This report shows that emergency CPB may be the only therapeutic option to establish stable hemodynamics in patients who do not respond to conventional resuscitation 
efforts. Prolonged reperfusion during CPB enables good recovery of the heart and may improve detoxification by increased elimination of an overdosed drug. This therapeutic option should be considered in patients with severe drug intoxication and hemodynamic instability despite prolonged resuscitation.

\section{REFERENCES}

1. Freed CR, Freedman MD. Lidocaine overdose and cardiac bypass support. JAMA 1985;253:3094-5.

2. Hendren WG, Schieber RS, Garrettson LK. Extracorporeal bypass for the treatment of verapamil poisoning. Ann Emerg Med 1989;18:984-7.

3. McVey FK, Corke CF. Extracorporeal circulation in the management of massive propranolol overdose. Anaesthesia 1991;46:744-6.

4. Schmidt W, Reissig M, Neuhaus K-L. Perkutane extracorporale Zirkulation bei kardiogenem Schock Aufgrund einer Mischintoxikation mit Metildigoxin, Nifedipin and Indapamid. Deutsch Med Wochenschr 1995;120:996-1002.

5. Yasui RK, Culclasure TF, Kaufman D, Freed CR. Flecainide overdose: Is cardiopulmonary support the treatment? Ann Emerg Med 1997;29:680-2. 